Western University

Scholarship@Western

$11-1-2016$

\title{
Effect of Left Atrial Wall Thickness on Radiofrequency Ablation Success.
}

Jiro Inoue

Allan C Skanes

Lorne J Gula

Maria Drangova

Follow this and additional works at: https://ir.lib.uwo.ca/biophysicspub

Part of the Medical Biophysics Commons

\section{Citation of this paper:}

Inoue, Jiro; Skanes, Allan C; Gula, Lorne J; and Drangova, Maria, "Effect of Left Atrial Wall Thickness on Radiofrequency Ablation Success." (2016). Medical Biophysics Publications. 89.

https://ir.lib.uwo.ca/biophysicspub/89 
1 Full Title: Effect of Left Atrial Wall Thickness on Radiofrequency Ablation Success

2 Short Title: Effect of LA Wall Thickness on RF Ablation

4 Authors:

$5 \quad$ Jiro Inoue $\mathrm{ahD}$ (jinoue@robarts.ca)

$6 \quad$ Allan C. Skanes ${ }^{b}$ MD FHRS FRCPC (askanes@uwo.ca)

7 Lorne J. Gulab MD FHRS FRCPC (Igula@uwo.ca)

$8 \quad$ Maria Drangova ${ }^{\mathrm{a}} \mathrm{PhD}$ (mdrangova@robarts.ca)

$10 \quad{ }^{a}$ Robarts Research Institute, Western University, 1151 Richmond St. N., London, ON

11 Canada N6A 3K7.

12 b Arrhythmia Service, London Health Sciences Center, Western University, 339

13 Windermere Rd., London, Ontario, Canada N6A 5A5.

15 Funding:

16 This study was supported by grant \#27790 from the Canadian Institutes of Health

17 Research. M.D. is a Career Investigator of the Heart and Stroke Foundation of Ontario.

19 Corresponding Author:

20 Jiro Inoue, Robarts Research Institute, Western University, 1151 Richmond St. N,

21 London, ON Canada N6A 3K7, Email: jinoue@robarts.ca, Phone: 519-902-9584 Fax:

$22 \quad 519-931-5789$ 
ABSTRACT:

25 Introduction

26 For radiofrequency (RF) ablation in thicker regions of the left atrium (LA) may require increased ablation energy in order to achieve effective transmural lesions.

28 Consequently, many cases of recurrent atrial fibrillation (AF) post ablation may be due to thicker-than-normal atrial tissue. The aim of this study was to test the hypotheses that patients with recurrent AF have thicker tissue overall and that electrical reconnection is more likely in regions of thicker tissue.

\section{Methods and Results}

Retrospective analysis was performed on 86 CT images acquired preoperatively from a cohort of 119 patients who had undergone RF ablation for AF. Of these, 33 patients experienced recurrence of $A F$ within one year of initial treatment and 29 returned for a repeat ablation. For each patient, LA wall thickness (LAWT) was measured from the images in 12 anatomical regions using custom software. Patients with recurrent AF had larger LAWT compared to successfully treated patients $(1.6 \pm 0.6 \mathrm{~mm}$ vs. $1.5 \pm 0.5 \mathrm{~mm}$, $p<0.001)$ and reconnection was found to be at regions of thicker tissue $(1.6 \pm 0.6 \mathrm{~mm}$, $p=0.038)$ compared to non-reconnected regions $(1.5 \pm 0.5 \mathrm{~mm})$. The superior right posterior wall of the LA was significantly related to both recurrence $(p=0.048)$ and reconnection $(p=0.014)$.

Conclusion Increased LAWT has a small, but significant effect on post-ablation recurrence and reconnection. Measures of LAWT may facilitate appropriate dosing of RF energy, but other factors will be critical in transmural lesion formation and ablation success.

KEYWORDS:

left atrium, wall thickness, CT, atrial fibrillation, radiofrequency catheter ablation, 
55 Radiofrequency (RF) catheter ablation has emerged as a front-line intervention for atrial fibrillation (AF), ${ }^{1}$ but requires long, circular lesions that are both continuous and transmural along the entire length. This challenge has been recently tackled using measures of contact force incorporated into indices of ablation lesion production. Correctly dosing RF energy has obvious limitations without knowing the thickness of underlying tissue. Overdosing may contribute to collateral damage and complications such as the rare, but frequently fatal, atrioesophageal fistula. ${ }^{2-4}$ Underdosing may limit transmurality and contribute to electrical reconnection and thus to a large number of repeat procedures. ${ }^{1,5}$ Furthermore, developing transmural lesions in thicker regions may be more sensitive to catheter instability. Knowledge of left atrial wall thickness (LAWT) is not currently incorporated into ablation delivery, despite previous research that shows clear inter- and intra-patient variability in LAWT. ${ }^{6-9}$ At present, clinical judgment is the major determinant of RF dosing, where clinicians may err on the side of underdosing energy rather than risk the fatal complications of overdosing RF. Dosing RF energy based on direct LAWT measurements may be an effective way to safely create continuous, transmural lesions.

The hypothesis that greater LAWT correlates with ablation failure has been scantly tested, and with limited results. One study examined the LAWT of patients undergoing RF ablation for paroxysmal AF and found that increased thickness seemed to correlate with ablation failure, but the difference was statistically significant at only 1 of 9 locations measured. ${ }^{10}$ Another study investigated the LAWT of RF ablation patients with hypertrophic cardiomyopathy and found significant, but small thickness differences in 2 of 11 locations and a statistically significant effect on ablation success could not be established. ${ }^{11}$

These previous studies examined overall success/failure of RF ablation in relation to LAWT at specific locations, but due to the number of individual ablation lesions created per intervention, a more localized analysis may be appropriate. By considering electrical reconnection at specific locations in relation to LAWT, the relationship between LAWT and ablation success can be examined with finer granularity.

Using a custom, semi-automated method of LAWT, we investigated two hypotheses on the relationship between greater LAWT and ablation success. First, that patients with recurrent $A F$ have thicker tissue compared to who were successfully treated by firsttime ablation, and second, that electrical reconnection was more likely at regions of thicker tissue.

\section{METHODS}

\section{Study Population}

The patient data for this study were drawn from a previous study. ${ }^{12}$ To summarize, 119 patients from a single site, diagnosed with paroxysmal $A F$, were originally enrolled for a study on the efficacy of pulmonary vein isolation (PVI) with incomplete antral ablation lines. Patients were preoperatively imaged with contrast-enhanced cardiac CT to assist with intraoperative guidance. Patients were approved for, and treated by, first-time RF 
ablation under CARTO (Biosense Webster Inc., USA) guidance using non-contact force catheters and randomized for either incomplete ablation lines - stopping when electrical isolation was achieved $(n=60)$, or complete ablation lines - continuing ablation until a complete loop was formed $(n=59)$. The study was performed before the availability of

104 force-contact catheters at our center. In both groups, pulmonary veins (PV) were isolated as pairs (superior and inferior together in a single loop). Patients were followed for twelve months, and in recurrent cases, repeat ablations were performed under CARTO guidance with non-contact force catheters, but imaging was not repeated. Recurrence was defined as symptomatic or asymptomatic AF of at least 30 seconds. Not all patients experiencing recurrence were treated a second time, but in those that were, ablation locations for repeat ablations were selected to achieve electrical isolation only and did not duplicate the original ablation pattern.

For the current study, 33 patients from the original study were excluded due to lack of CT images $(n=30)$, outcome data $(n=2)$, or abandonment of the procedure $(n=1)$. All treatments were completed before the inception of this study. The current study was approved by the Research Ethics Board of Western University.

\section{CT Imaging and 3D Image Processing}

CT images were acquired using a GE Discovery CT750 HD or GE LightSpeed VCT (GE Healthcare, UK) using a clinical protocol for contrast-enhanced cardiac CT imaging for $\mathrm{RF}$ ablation. Scans were gated to generate images at $70 \%$ of the R-R interval; $100 \mathrm{mg}$ of Isovue 370 or Visipaque 270 was injected intravenously to enhance the blood pool. Pixel spacing varied from 0.39 to $0.88 \mathrm{~mm}$ and slice thickness was 0.625 or $1.25 \mathrm{~mm}$. Prior to the ablation procedures, 3D models were constructed from the CT images by an expert electrophysiology technician for integration with the CARTO system.

\section{Computer-Assisted LAWT Measurement}

A computer-assisted LAWT measurement method was developed using the MeVisLab (MeVis Medical Solutions AG, Germany) medical imaging software development framework. This software is capable of calculating a LAWT value for any point on the endocardium of the left atrial wall based on the Hounsfield unit $(\mathrm{HU})$ intensities of the CT image near that point. This method combines the thresholding approach of classifying left atrial anatomy, ${ }^{11,13-16}$ patient-specific modeling of image intensity in CT, the ability to measure in any $3 \mathrm{D}$ direction, and the precision and repeatability of automated measurement.

For each CT image, patient-specific HU thresholds were determined for the endocardial boundary separating the blood pool from myocardium, and the epicardial boundary separating the myocardium from fat or other surrounding tissues. The expected intensities for blood and myocardium were first determined by sampling large, contiguous regions on single axial image slices and calculating the mean and standard deviation intensities of the samples. The blood pool was sampled inside the left atrium and the myocardium was sampled at either the apex or the superior aspect of the left ventricle. The endocardial threshold was chosen to be the mean of the blood pool and myocardium samples, and the epicardial threshold was chosen to be two standard 
deviations below the mean myocardial intensity. This was necessary due to the possibility of multiple types of tissues being adjacent to the epicardial side of the atrial wall and the resulting variation in the ideal threshold value.

Measurement locations were selected using an interactive graphical user interface. Elements of this interface are shown in Figure 1a-b. A mouse was used to manually select individual measurement locations on the 3D model of the left atrium either by directly choosing a location on the model, or by selecting a nearby location on a 2D CT slice. The 3D model was smoothed using Laplacian mesh smoothing (5 passes, smoothing factor of 0.9 ) to reduce angulation errors in the direction of the ray perpendicular to the model surface. A line segment was then defined at the measurement location, perpendicular to the surface, extending from $5 \mathrm{~mm}$ inside to 10 $\mathrm{mm}$ outside the atrium.

The CT image was resampled using trilinear interpolation at $0.1 \mathrm{~mm}$ intervals along this line to obtain a $\mathrm{HU}$ intensity profile, and the intensity profile was then classified into sections of blood pool, myocardium, or fat/external tissue based on the patient-specific thresholds. The section of the intensity profile corresponding to the atrial wall was then selected, and the length of myocardial tissue in this section was recorded as the thickness measurement. An example profile and measurement is shown in Figure 1c. Each profile was manually checked for indeterminate cases or obvious misclassification. In these cases, the measurement was not used, and the point selection was repeated.

\section{Experimental Data Collection}

The regions of the left atrium targeted for ablation were subdivided into 12 regions as shown in Figure 2. Due to difficulties in measuring and ablating directly on the left lateral ridge, the left anterior locations (superior and inferior) were defined inside the PV, within $\sim 10 \mathrm{~mm}$ of the ostia. The LAWT for each region was measured using the previously described method five times, the high and low values were discarded, and the mean of the three middle values was considered to be the thickness for the region. Two regions where reasonable measurements could not be determined after many attempts, and 13 regions where the measurement range (the difference between the largest and smallest of the three middle measurements) was large (more than three standard deviations over the mean measurement range for all regions) were also excluded. The remaining 1017 measurements $(99 \%)$ were used for the analysis of recurrence.

For the analysis of reconnection, it was necessary to classify each region as reconnected or not reconnected. In the original study, ${ }^{12}$ patients were randomized to initial PVI by either complete ablation lines or incomplete ablation lines, where ablation was concluded when the PV demonstrated entry and exit block. If a second intervention was performed, sites of previous ablation were assessed for conduction recovery and if recovery was found, ablated again. Reconnected regions are those that were ablated in both the initial treatment and the second treatment. Non-reconnected regions are those that were ablated once only, on the first treatment. All ablated regions in patients that did not experience recurrence were considered to be non-reconnected. Regions that were never ablated in the initial treatment due to the use of incomplete ablation lines ( $n$ 
$192=57$ regions) were excluded and patients that experienced recurrence but did not 193 undergo a second treatment (4 patients, $n=44$ regions) were excluded from this analysis. In total, 70 regions reconnected and 846 regions were not reconnected.

\section{Statistical Analysis}

Descriptive statistics for CT images and LAWT measurements were collected. All continuous data are expressed as mean \pm standard deviation. Statistical analysis was performed using Prism 6 (Graphpad Software Inc., USA) with a $p<0.05$ considered to be statistically significant.

Before testing for statistical significance, normality of all measurements was tested using the D'Agostino-Pearson normality test. The relationship between LAWT and recurrence was tested by comparing the regional LAWTs of repeated vs. non-repeated cases using 2-way ANOVA. Post hoc analysis using Fisher's LSD (unprotected, twotailed) on subgroups was performed to find specific regions where the effect of thickness was most significant.

The relationship between the LAWT and local reconnection was tested by comparing the wall thicknesses of reconnected vs. non-reconnected regions. Due to the small numbers of repeated ablation points, all measurements were pooled and tested using the two-tailed Mann-Whitney $U$ test. Post hoc analysis using Fisher's LSD (unprotected, two-tailed) on subgroups was performed to find specific regions of thickness difference.

\section{RESULTS \\ Patient Characteristics}

Baseline and imaging characteristics of the patients are summarized in Table 1. In general, the mean intensities of myocardium were fairly consistent, but there was considerable variability (noise) within each image. There was much higher variability in the mean intensity of the blood pool due to the effect of variable mixing of contrast agent and blood. Thus the endocardial threshold $(250 \pm 55 \mathrm{HU})$ was much more variable compared to the epicardial threshold $(32 \pm 30 \mathrm{HU})$. The distributions of calculated threshold values are shown in Figure 3.

\section{Overall measurements and Descriptive statistics}

Across all patients, LAWT was found to be $1.5 \pm 0.5 \mathrm{~mm}$ but with significant variation between regions ( $p<0.001$ by 1 -way ANOVA). The distribution of measurements by the D'Agostino-Pearson normality test was found to be non-normal overall, but with some subsets of the data passing as significantly close to normal. Thus, non-parametric statistics were used for the reconnection analysis due to the small number of individual reconnection locations. A summary of mean measurements by region is given in the second column of Table 2. Interestingly, the right side of the left atrium was found to be significantly thicker than the left side in all six relative locations (e.g. right roof vs. left roof; $p<0.001$ overall by 2 -way ANOVA, $p<0.01$ for each of the six pairs by Fisher's uncorrected LSD post-test.)

\section{Effect of LAWT on Recurrence}

Preprint of Inoue J, Skanes AC, Gula LJ, Drangova M.

J Cardiovasc Electrophysiol. 2016 Nov;27(11):1298-1303. doi: 10.1111/jce.13065. Epub 2016 Sep 16. 
ANOVA showed that increased LAWT was found to significantly correlate with increased recurrence $(p=0.001)$. Post hoc analysis showed significant effects at three locations: the right high posterior $(p=0.048)$, right low anterior $(p=0.024)$, and left high

\section{DISCUSSION}

\section{LAWT Correlates with Recurrence and Reconnection}

We have described a semi-automated method of regional CT-derived measurement of LAWT and tested whether these measures are associated with clinically important outcomes. The results of this analysis show that in RF ablation of the left atrium in paroxysmal AF patients, increased LAWT correlates with poorer ablation outcomes. Regions of thicker tissue are associated with sites of electrical reconnection and increased chance of recurrence. These results augment and clarify results by Suenari et al., ${ }^{10}$ which showed that measurements at the left lateral ridge correlated significantly with recurrence, and by Takahashi et al., ${ }^{13}$ which showed ATP-provoked dormant conduction in areas of thicker tissue. These related studies used slightly different measurement and analysis methods, but support the overall hypothesis that thicker tissue is more difficult to ablate successfully.

\section{Importance of LAWT:}

Despite the statistical significance of the main results, the clinical significance of LAWT is uncertain. The statistical results show a link between LAWT and ablation failure but the magnitudes of the mean detected differences are small, both in absolute terms and relative to the overall variation in LAWT. Takahashi et al. ${ }^{13}$ similarly showed significant but small differences, as did Suenari et al. ${ }^{10}$

Can such small differences in LAWT be a real contributor to ablation outcomes? Clearly, LAWT is but one important parameter impacting outcomes. Permanent antral $\mathrm{PVI}$ requires a continuous transmural linear lesion encircling the PV. It is likely that catheter stability, power, force contact (unavailable for this study) and thickness all interact to determine both contiguity and transmurality at any site(s). As force contact and catheter stability were not evaluated in this study, their contribution to lesion failure cannot be evaluated. However, given an overall variability in both contact force and catheter stability during ablation, it is not surprising that thicker tissue is more resistant

Preprint of Inoue J, Skanes AC, Gula LJ, Drangova M.

J Cardiovasc Electrophysiol. 2016 Nov;27(11):1298-1303. doi: 10.1111/jce.13065. Epub 2016 Sep 16. 
to ablation, implying that there may be a higher threshold for successful ablation at these sites. Thicker regions may also require better contact during ablation due to the

It is striking that force contact and catheter stability have received more attention than LAWT in determining ablation outcomes, likely because of the difficulty in accurately measuring LAWT. As ablation algorithms incorporate force-time integrals and power to measure RF dose and predict lesion depth, LAWT will likely become investigated more extensively and evaluated as the ablation target. Recent advances in controlling catheter contact force ${ }^{17}$ rather than simply measuring it, will likely allow more precise delivery of a prescribed RF dose in the future. Effective use of this technology will require equally precise targets. With further validation, automated measurements with graphical visualizations such as shown in Figure 4, may be used to assist in determining these targets.

\section{Limitations}

Small sample sizes, especially in the number of reconnection locations, limited the statistical power of some of our subgroup analyses. However, the combined data confirmed our hypothesis that, in general, thicker tissues are more resistant to transmural ablation, resulting in greater recurrence and reconnection.

All patients were assumed to have arrhythmias originating in the PV but it is possible that some non-PV triggers contributed to AF recurrence. Although we could not identify these cases directly, PV ablation gap production appeared to be related to LAWT. We are aware of no relationship to non-PV triggers that would systematically bias the observation related to LAWT.

The measurement method developed for this study is based on a patient-specific, mathematical model of CT images and has not been rigorously validated for accuracy. Validating the accuracy of LAWT measurement is difficult because of a lack of a gold standard for LAWT measurements - image-based methods are not an independent standard to measure against, and pathology specimens are known to shrink. To the best of our knowledge, there is no validated method of LAWT measurement. Validation of repeatability has not been tested with multiple observers. Due to the use of automation however, this method allows objective, repeatable measurements that are suitable as a relative measure of LAWT. Low image quality and challenging anatomy also create difficulties in measuring LAWT, decreasing the statistical power of this. Future use of LAWT for ablation planning may require optimized CT protocols to better isolate the atrial wall and derive accurate thickness measurements.

\section{CONCLUSION}

A semi-automated, CT-based LAWT measure has been developed and has been shown to correlate to clinically relevant outcomes: post-operative recurrence of $\mathrm{AF}$, and specifically with local electrical reconnection. This measure may be used to assist in dosing RF energy, but given the small magnitudes of the detected differences, other factors (such as contract force or catheter stability) will be critical in transmural lesion formation and ablation success. Increasing RF ablation success rates will require an

Preprint of Inoue J, Skanes AC, Gula LJ, Drangova M.

J Cardiovasc Electrophysiol. 2016 Nov;27(11):1298-1303. doi: 10.1111/jce.13065. Epub 2016 Sep 16. 
328 improved understanding of dose target parameters such as LAWT in combination with 329 the development of methods of improving the accuracy of RF dosing.

ACKNOWLEDGMENTS

332 We would like to acknowledge the assistance of Paul Purves, Lindsay Hillock and

333 Stephany Hare for assistance with the data collection, and Rosanna Turner for

334 assistance with research ethics. Funding: This work was supported the Canadian

335 Institutes of Health Research grant number 27790. M.D. is a Career Investigator of the

336 Heart and Stroke Foundation of Ontario. 
339 [1] Cappato R, Calkins H, Chen SA, Davies W, lesaka Y, Kalman J, Kim YH, Klein survey on the methods, efficacy, and safety of catheter ablation for human atrial fibrillation. Circ Arrhythm Electrophysiol 2010; 3:32-38.

[2] Sonmez B, Demirsoy E, Yagan N, Unal M, Arbatli H, Sener D, Baran T, llkova F: A fatal complication due to radiofrequency ablation for atrial fibrillation: atrioesophageal fistula. Ann Thorac Surg 2003; 76:281-283.

[3] Scanavacca MI, D'Avila A, Parga J, Sosa E: Left atrial-esophageal fistula following radiofrequency catheter ablation of atrial fibrillation. J Cardiovasc Electrophysiol 2004; 15:960-962.

[4] Pappone C, Oral H, Santinelli V, Vicedomini G, Lang CC, Manguso F, Torracca L, Benussi S, Alfieri O, Hong R, Lau W, Hirata K, Shikuma N, Hall B, Morady F: Atrio-esophageal fistula as a complication of percutaneous transcatheter ablation of atrial fibrillation. Circulation 2004; 109:2724-2726.

[5] Callans DJ, Gerstenfeld EP, Dixit S, Zado E, Vanderhoff M, Ren JF, Marchlinski FE: Efficacy of repeat pulmonary vein isolation procedures in patients with recurrent atrial fibrillation. J Cardiovasc Electrophysiol 2004; 15:1050-1055.

[6] Ho SY, Sanchez-Quintana D, Cabrera JA, Anderson RH: Anatomy of the left atrium: implications for radiofrequency ablation of atrial fibrillation. J Cardiovasc Electrophysiol 1999; 10:1525-1533.

[7] Platonov PG, Ivanov V, Ho SY, Mitrofanova L: Left atrial posterior wall thickness in patients with and without atrial fibrillation: data from 298 consecutive autopsies. J Cardiovasc Electrophysiol 2008; 19:689-692.

[8] Sanchez-Quintana D, Cabrera JA, Climent V, Farre J, Mendonca MC, Ho SY: Anatomic relations between the esophagus and left atrium and relevance for ablation of atrial fibrillation. Circulation 2005; 112:1400-1405.

[9] Hall B, Jeevanantham V, Simon R, Filippone J, Vorobiof G, Daubert J: Variation in left atrial transmural wall thickness at sites commonly targeted for ablation of atrial fibrillation. J Interv Card Electrophysiol 2006; 17:127-132.

[10] Suenari K, Nakano Y, Hirai Y, Ogi H, Oda N, Makita Y, Ueda S, Kajihara K, Tokuyama T, Motoda C, Fujiwara M, Chayama K, Kihara Y: Left atrial thickness under the catheter ablation lines in patients with paroxysmal atrial fibrillation: insights from 64-slice multidetector computed tomography. Heart Vessels 2012; 28:360-368.

[11] Hayashi H, Hayashi M, Miyauchi Y, Takahashi K, Uetake S, Tsuboi I, Yodogawa K, Iwasaki YK, Shimizu W: Left atrial wall thickness and outcomes of catheter ablation for atrial fibrillation in patients with hypertrophic cardiomyopathy. J Interv Card Electrophysiol 2014; 40:153-160.

[12] Gula LJ, Leong-Sit P, Manlucu J, Hillock L, Yee R, Tang ASL, Klein GJ, Skanes AC: Pulmonary vein isolation with incomplete antral ablation lines: Is more ablation necessary? Results of a randomized trial. J Cardiovasc Electrophysiol 2015; 27:298-302.

[13] Takahashi K, Okumura Y, Watanabe I, Nagashima K, Sonoda K, Sasaki N, Kogawa R, Iso K, Ohkubo K, Nakai T, Hirayama A: Relation Between Left Atrial

Preprint of Inoue J, Skanes AC, Gula LJ, Drangova M.

J Cardiovasc Electrophysiol. 2016 Nov;27(11):1298-1303. doi: 10.1111/jce.13065. Epub 2016 Sep 16. 
Wall Thickness in Patients with Atrial Fibrillation and Intracardiac Electrogram

[14] Dewland TA, Wintermark M, Vaysman A, Smith LM, Tong E, Vittinghoff E, Marcus GM: Use of Computed Tomography to Identify Atrial Fibrillation Associated Differences in Left Atrial Wall Thickness and Density. Pacing Clin Electrophysiol 2013; 36:55-62.

[15] Abbara S, Desai JC, Cury RC, Butler J, Nieman K, Reddy V: Mapping epicardial fat with multi-detector computed tomography to facilitate percutaneous transepicardial arrhythmia ablation. Eur J Radiol 2006; 57:417-422.

[16] Tadros TM, Massaro JM, Rosito GA, Hoffmann U, Vasan RS, Larson MG, Keaney JF, Lipinska I, Meigs JB, Kathiresan S, O'Donnell CJ, Fox CS, Benjamin EJ: Pericardial fat volume correlates with inflammatory markers: the Framingham Heart Study. Obesity (Silver Spring) 2010; 18:1039-1045.

[17] Gelman D, Skanes A, Tavallaei M, Drangova M: Design and Evaluation of a Catheter Contact- Force Controller for Cardiac Ablation Therapy. IEEE Trans Biomed Eng 2016; http://dx.doi.org/10.1109/TBME.2016.2525929. 

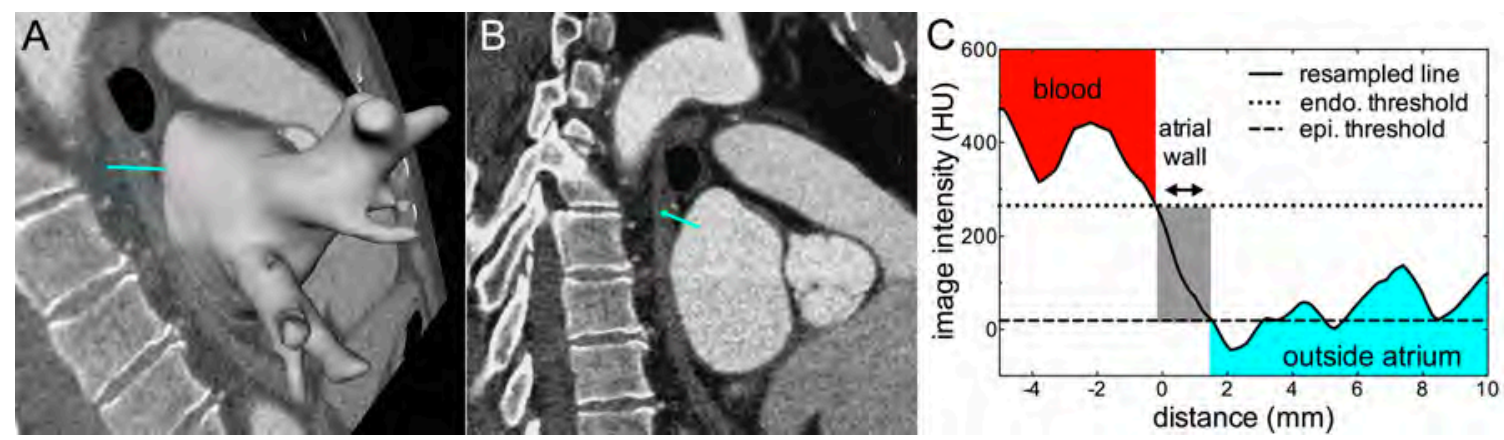

402 Figure 1 Measurement of LAWT. A: A patient-specific model of the left atrial blood

403 pool is illustrated along with a line perpendicular to the LA surface (cyan); a 2D CT

404 image re-sliced in the direction of the selected line is also shown. B: The CT image was

405 resampled along the selected ray from inside the atrium toward the epicardium. Actual

406 calculations were made in 3D. C: The atrial wall was identified from the CT image

407 intensity of the resampled line using the defined endo- and epicardial thresholds. 


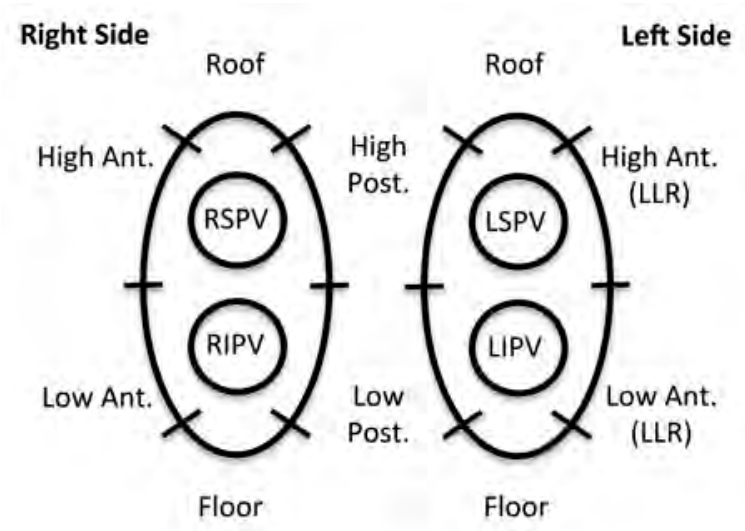

409 Figure 2 Schematic of LAWT measurement locations. 12 locations (6 per side)

410 were selected around the pulmonary-vein antra where circumferential pulmonary vein

411 ablation would be performed. Left lateral ridge locations were taken inside the

412 pulmonary vein within $\sim 10 \mathrm{~mm}$ of the antrum. Ant $=$ anterior; Post $=$ posterior; $\mathrm{LLR}=$ left

413 lateral ridge; RSPV = right superior pulmonary vein; RIPV = right inferior pulmonary

414 vein; LSPV = left superior pulmonary vein; LIPV = left inferior pulmonary vein. 


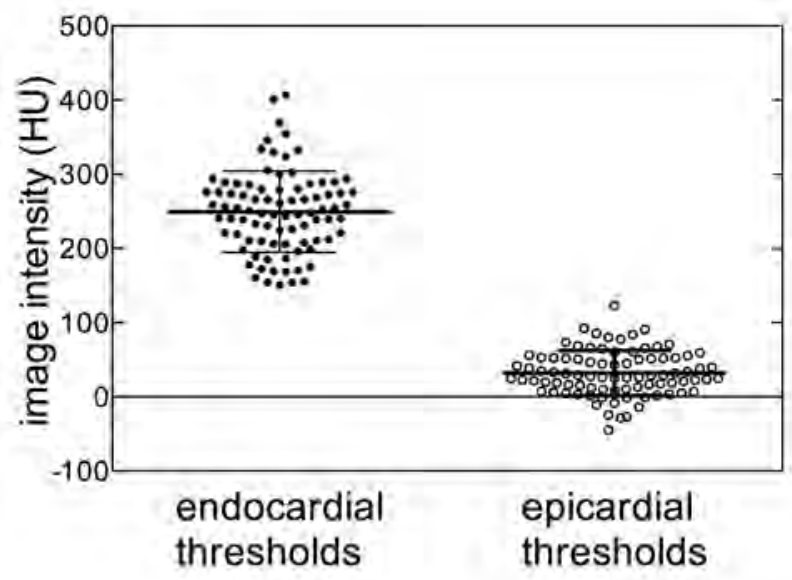

416

417 Figure 3 Graph of calculated endocardial and epicardial thresholds used to

418 determine boundaries of the atrial wall. Mean and standard deviation of the

419 measurements are also plotted.

420

Preprint of Inoue J, Skanes AC, Gula LJ, Drangova M.

J Cardiovasc Electrophysiol. 2016 Nov;27(11):1298-1303. doi: 10.1111/jce.13065. Epub 2016 Sep 16. 


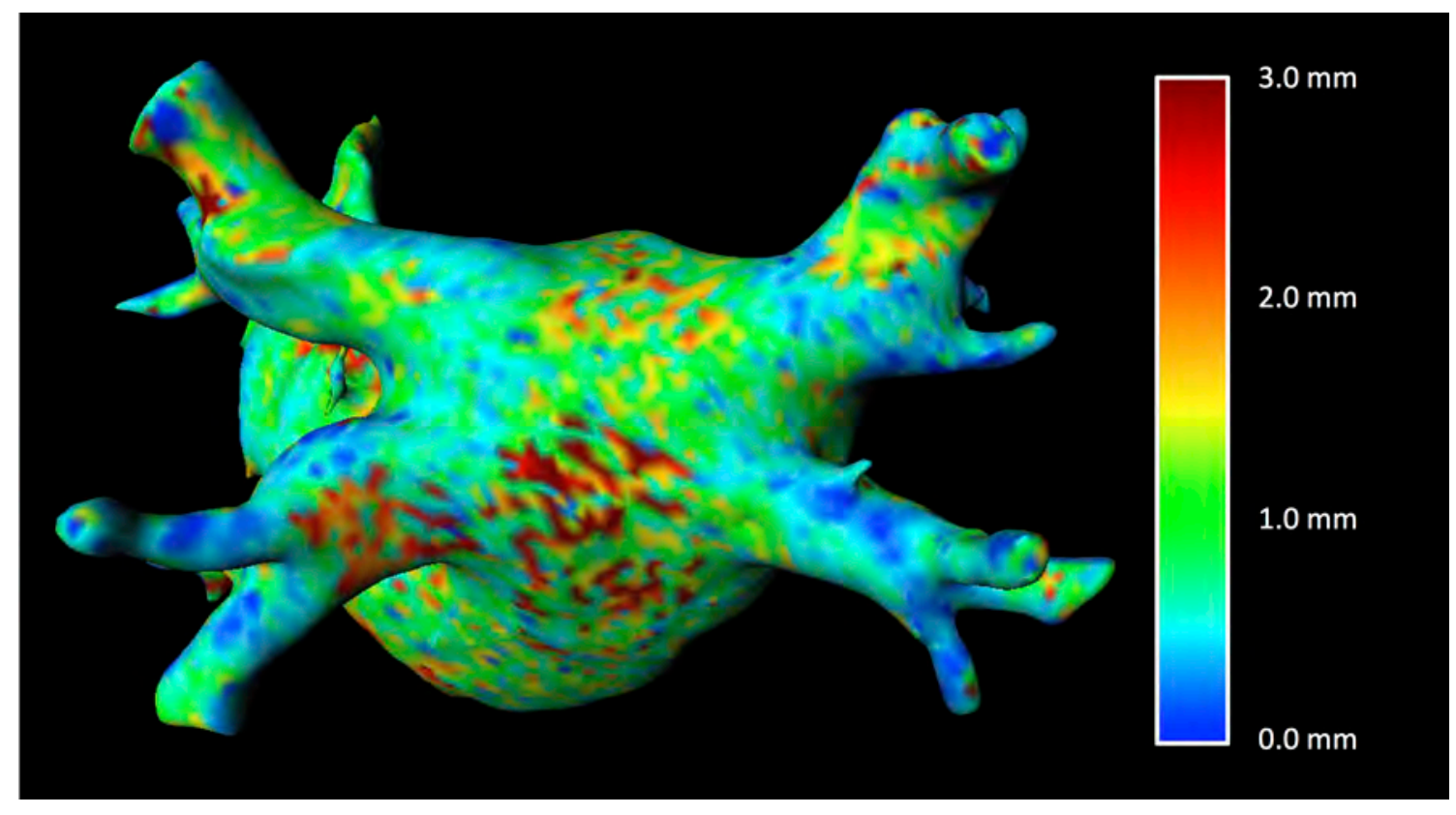

422 Figure 4 Posterior view of 3D rendering of example left atrium with color-coded

423 thickness map. Measurements were generated automatically and applied without

424 manual vetting. Slow variation in thickness from region-to-region can be seen by shifts

425 in average color. Rapid color variation is due to noise in the CT data and very thick

426 measurements between the inferior pulmonary veins are caused by misclassification of

427 the esophagus rather than exceptionally thick atrial wall. 
429 Table 1 Baseline characteristics of patients.

\begin{tabular}{|l|l|}
\hline Characteristic & \\
\hline Clinical & \\
\hline Total number of patients & 86 \\
\hline Age (years) & $59.7 \pm 8.8$ \\
\hline Male Sex & $65(75.6 \%)$ \\
\hline Hypertension & $34(39.5 \%)$ \\
\hline Diabetes Mellitus & $3(3.5 \%)$ \\
\hline Stroke/TIA/PAE & $1(1.2 \%)$ \\
\hline Congestive Heart Failure & $1(1.2 \%)$ \\
\hline Amiodarone & $18(20.9 \%)$ \\
\hline Sotalol & $19(22.1 \%)$ \\
\hline Beta Blocker & $17(19.8 \%)$ \\
\hline Calcium Channel Blocker & $11(12.8 \%)$ \\
\hline Digoxin & $1(1.2 \%)$ \\
\hline Left Atrial Size (mm) & $40.8 \pm 6.0(\mathrm{n}=70)$ \\
\hline CT-image derived & \\
\hline Blood Pool Intensity Mean (HU) & $388 \pm 96$ \\
\hline Blood Pool Intensity SD (HU) & $50 \pm 15$ \\
\hline Muscle Intensity Mean (HU) & $111 \pm 22$ \\
\hline Muscle Intensity SD (HU) & $40 \pm 11$ \\
\hline Endocardial Boundary Threshold (HU) & $250 \pm 55$ \\
\hline Epicardial Boundary Threshold (HU) & $32 \pm 30$ \\
\hline
\end{tabular}

431 Values shown are number (\%) or mean \pm SD between subjects. ${ }^{*}$ Clinically derived from

432 echocardiograms. $\mathrm{HU}=$ Hounsfield unit. 
434 Table 2 Left atrial wall thickness by region. Recurrence of atrial fibrillation vs. no 435 recurrence.

436

\begin{tabular}{|l|c|c|c|c|}
\hline \multicolumn{1}{|c|}{ Region } & $\begin{array}{c}\text { All } \\
\text { images } \\
(\boldsymbol{n}=\mathbf{8 6})\end{array}$ & $\begin{array}{c}\text { No recurrence } \\
(\boldsymbol{n}=\mathbf{5 3})\end{array}$ & $\begin{array}{c}\text { Recurrenc } \\
\mathbf{e} \\
(\boldsymbol{n}=\mathbf{3 3})\end{array}$ & $\begin{array}{c}\boldsymbol{P} \text { - } \\
\text { value }\end{array}$ \\
\hline & & & & \\
\hline All regions & $1.5 \pm 0.5$ & $1.5 \pm 0.5$ & $1.6 \pm 0.6$ & 0.001 \\
\hline Right roof & $1.7 \pm 0.7$ & $1.7 \pm 0.6$ & $1.8 \pm 0.8$ & 0.404 \\
\hline $\begin{array}{l}\text { Right high } \\
\text { anterior }\end{array}$ & $1.7 \pm 0.5$ & $1.7 \pm 0.6$ & $1.7 \pm 0.5$ & 0.838 \\
\hline Right low anterior & $1.6 \pm 0.5$ & $1.5 \pm 0.4$ & $1.8 \pm 0.7$ & 0.024 \\
\hline $\begin{array}{l}\text { Right high } \\
\text { posterior }\end{array}$ & $1.7 \pm 0.5$ & $1.6 \pm 0.4$ & $1.8 \pm 0.6$ & 0.048 \\
\hline $\begin{array}{l}\text { Right low } \\
\text { posterior }\end{array}$ & $1.5 \pm 0.5$ & $1.5 \pm 0.5$ & $1.5 \pm 0.4$ & -0.945 \\
\hline Right floor & $1.6 \pm 0.5$ & $1.5 \pm 0.5$ & $1.6 \pm 0.6$ & 0.281 \\
\hline Left roof & $1.5 \pm 0.6$ & $1.4 \pm 0.5$ & $1.5 \pm 0.7$ & 0.239 \\
\hline Left high anterior & $1.4 \pm 0.5$ & $1.3 \pm 0.4$ & $1.5 \pm 0.6$ & 0.023 \\
\hline Left low anterior & $1.4 \pm 0.5$ & $1.4 \pm 0.5$ & $1.4 \pm 0.4$ & 0.890 \\
\hline Left high posterior & $1.4 \pm 0.5$ & $1.3 \pm 0.4$ & $1.4 \pm 0.6$ & 0.176 \\
\hline Left low posterior & $1.3 \pm 0.4$ & $1.3 \pm 0.4$ & $1.3 \pm 0.3$ & -0.590 \\
\hline Left floor & $1.4 \pm 0.4$ & $1.3 \pm 0.5$ & $1.4 \pm 0.4$ & 0.434 \\
\hline & & & & \\
\hline
\end{tabular}

Measurements shown as mean $\pm \mathrm{SD}$ in $\mathrm{mm}$.

$438 P$-values per 2-way (region, recurrence) ANOVA for all regions. Fisher's LSD for 439 individual regions. 
442 Table 3 Left atrial wall thickness by region. Reconnection vs. no reconnection.

\begin{tabular}{|l|c|c|c|c|}
\hline \multicolumn{1}{|c|}{ Region } & All ablated & $\begin{array}{c}\text { No } \\
\text { reconnection }\end{array}$ & $\begin{array}{c}\text { Reconnecti } \\
\text { on }\end{array}$ & $P$-value \\
\hline & & & & \\
\hline All regions & $1.5 \pm 0.5$ & $1.5 \pm 0.5(846)$ & $\begin{array}{c}1.6 \pm 0.6 \\
(70)\end{array}$ & 0.038 \\
\hline Right roof & $1.8 \pm 0.7$ & $1.7 \pm 0.6(65)$ & $2.0 \pm 0.8(9)$ & 0.092 \\
\hline Right high anterior & $1.7 \pm 0.6$ & $1.7 \pm 0.6(71)$ & $1.5 \pm 0.4(4)$ & -0.475 \\
\hline Right low anterior & $1.6 \pm 0.6$ & $1.6 \pm 0.6(76)$ & $1.7 \pm 0.6(5)$ & 0.555 \\
\hline $\begin{array}{l}\text { Right high } \\
\text { posterior }\end{array}$ & $1.7 \pm 0.5$ & $1.6 \pm 0.5(72)$ & $2.1 \pm 0.6(7)$ & 0.014 \\
\hline Right low posterior & $1.5 \pm 0.5$ & $1.5 \pm 0.5(67)$ & $\begin{array}{c}1.6 \pm 0.5 \\
(10)\end{array}$ & 0.524 \\
\hline Right floor & $1.6 \pm 0.5$ & $1.6 \pm 0.5(73)$ & $1.8 \pm 0.6(6)$ & 0.363 \\
\hline Left roof & $1.5 \pm 0.6$ & $1.5 \pm 0.6(70)$ & $1.3 \pm 0.3(7)$ & -0.352 \\
\hline Left high anterior & $1.3 \pm 0.4$ & $1.3 \pm 0.4(71)$ & $1.5 \pm 0.5(4)$ & 0.608 \\
\hline Left low anterior & $1.4 \pm 0.5$ & $1.4 \pm 0.5(74)$ & $1.5 \pm 0.4(5)$ & 0.647 \\
\hline Left high posterior & $1.3 \pm 0.5$ & $1.3 \pm 0.5(69)$ & $1.3 \pm 0.3(5)$ & 0.999 \\
\hline Left low posterior & $1.3 \pm 0.4$ & $1.3 \pm 0.4(70)$ & $1.2 \pm 0.3(5)$ & -0.833 \\
\hline Left floor & $1.4 \pm 0.5$ & $1.4 \pm 0.5(68)$ & $1.3 \pm 0.2(3)$ & -0.953 \\
\hline & & & & \\
\hline
\end{tabular}

Measurements shown as mean $\pm \mathrm{SD}$ in $\mathrm{mm}$. 